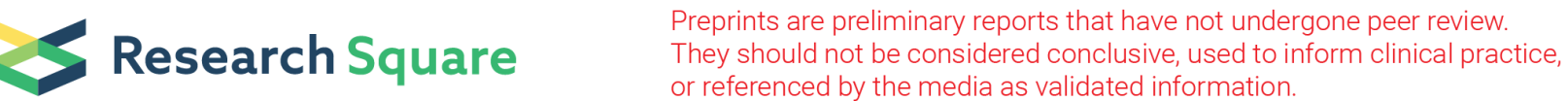

\section{Frequency and severity of Covid-19 in patients treated with biological Disease Modifying Anti- Rheumatic Drugs (bDMARDs) for inflammatory rheumatic disease. A case-control study}

\section{Dr. Anne LOHSE}

Hôpital Nord Franche Comté

Dr. Marie BOSSERT

Hôpital Nord Franche Comté

Dr. Ana-Maria BOZGAN

Hôpital Nord Franche Comté

Charlotte BOURGOIN

Hôpital Nord Franche Comté

Dr. Aline CHARPENTIER

Hôpital Nord Franche Comté

Dr. Cerise GUILLOCHON

Hôpital Nord Franche Comté

Dr. Julie KESSLER

Hôpital Nord Franche Comté

Dr. Jean-Charles BALBLANC

Hôpital Nord Franche Comté

Dr. Thierry CONROZIER ( $\nabla$ thierry.conrozier@hnfc.fr)

Hôpital Nord Franche Comté

\section{Research Article}

Keywords: SARS-CoV-2, COVID-19, bDMARDs, biologics, TNF a inhibitors, IL-6 inhibitors, JAK-inhibitors, abatacept, rituximab, rheumatoid arthritis, ankylosing spondylitis, psoriatic arthritis

Posted Date: August 2nd, 2020

DOI: https://doi.org/10.21203/rs.3.rs-50490/v1

License: (9) This work is licensed under a Creative Commons Attribution 4.0 International License. Read Full License 


\section{Abstract}

The aim of the study was to assess the impact (frequency and severity) of Covid-19 on patients treated with biological Disease Modifying Anti-Rheumatic Drugs (bDMARDs) for inflammatory rheumatic disease and to compare it to a control group consisting of patients with musculoskeletal conditions not treated with bDMARDs.

Patients and methods:

A case control study in 200 outpatients with musculoskeletal conditions. 100 consecutive patients who have been treated with bDMARDs and 100 other consecutive patients who did not take bDMARDs were asked to complete a 15-item standardized questionnaire regarding demographic data. The following information was recorded: gender, age, weight, height, body mass index, professional activity, family status, total number of children and number of children under 18, rheumatic disease diagnosis, current treatment for rheumatism, type of containment, close contact with Covid-19 patients, Covid-19 symptoms, Covid-19 test result and hospitalization for Covid-19.

Results:

bDMARD patients mostly suffered from rheumatoid arthritis, or RA, (47\%) and ankylosing spondylitis (42\%). The most prescribed bDMARDs were TNFa inhibitors (57\%), IL-6 blockers (12\%) and JAK inhibitors $(11 \%)$. The mean duration of the current biological treatment was 38.6 months. Patients from the control group were suffering chiefly from osteoarthritis (45\%) and RA (21\%). Compared to the control group, patients treated with bDMARDs were 10 years younger $(p<0.001)$, fewer were retired ( $56 \%$ versus $31 \%$ ) and more were on sick or incapacity leave ( $6 \%$ versus $18 \%$ ). During lockdown, they were more likely to be working from home or working short term ( $27 \%$ versus $9 \%) .18$ patients from the bDMARDs group stopped biological treatment: one because of Covid-19 evidenced by PCR, 11 because of symptoms suggesting Covid- 19 and only six from fear of contracting the disease. 12 patients, including the one Sars-CoV- $2+$, resumed their treatment after a few weeks of interruption. There was no severe Covid-19 infection in the bDMARDs group. Among the three patients from the control group who had contracted Covid-19, one developed a very severe disease.

Conclusion :

This case-control study did not show an increase in the frequency or severity of Covid-19 in subjects suffering from chronic inflammatory rheumatism treated with biotherapies. Larger-scale studies are necessary before affirming that biologics do not expose patients to an increased risk of disease and complications.

\section{Introduction}


The outbreak of the coronavirus disease 2019 (Covid-19) (1) has left behind more than 500,000 global deaths among the 10 million officially diagnosed cases. Death from Sars-coV-2 virus is chiefly due to an acute respiratory distress syndrome, but also to a wide range of organ dysfunctions (2-6). In children and young adults, Covid- 19 is usually mild, and not even symptomatic. On the contrary, in older and frail people, the SARS-CoV-2 virus can result in multiple organ failure, leading to death in about $4 \%$ of cases (2). Rheumatologists are on the very frontline in the management of COVID-19, although very few musculoskeletal disorders have been reported (7). The use of hydroxychloroquine for treating Covid-19, based on the antiviral activity of chloroquine (9-10) and above all that of Tocilizumab (TCZ) (11-20), a humanized anti- IL-6 receptor antibody widely used in the treatment of rheumatoid arthritis and juvenile idiopathic arthritis, has put rheumatologists in the spotlight $(21,22)$. Yet TCZ, like other biological Disease Modifying Anti-Rheumatic Drugs (bDMARDs), has been classified as a potentially immunosuppressive drug due to the increased risk of severe infection in patients treated with bDMARDs (23). Three questions must be raised: $i$ ) Is it reasonable for patients treated with bDMARDs to continue the treatment during the epidemic phase of Covid-19?; ii) How do we manage these patients if they are infected with SARS-CoV-2?; and iii) Can these patients who are 'at risk of serious infection' continue to work before an effective vaccine is available? The French Society of Rheumatology answered these issues on 21 March 2020 and sent its recommendations to all French rheumatologists. The main points to be underlined were: $i$ ) Persons with immunosuppression acquired by immunosuppressive therapy, biotherapy and/or corticosteroid therapy at an immunosuppressive dose may request to be put on sick leave; ii) If there is no sign of a Covid-19 infection, you can continue your treatment (cDMARDs, bDMARDS, corticosteroid therapy); iii) If there are signs of Covid-19 infection (fever, cough, shortness of breath, muscle pain), stop treatment for your rheumatism, except for corticosteroids and hydroxychloroquine. NSAIDs must be stopped; and iv) All patients should drastically restrict their social interactions and postpone nonemergency care. However, the preliminary reports showing the beneficial effects of a IL-6 and IL-1 blockade in Sars-CoV-2 ARDS $(18,19,24)$ can paradoxically suggest a possible 'protective' effect of certain bDMARDs on Covid-19 severity. The Nord Franche-Comté hospital is located in north-eastern France, an area severely impacted by the Covid-19 outbreak (25). In our hospital, between 1 March and 30 June 2020, more than 700 patients were hospitalized for Covid-19 and 180 died. In the three neighbouring departments (Haut-Rhin, Doubs and Haute-Saône), about 4,500 patients were hospitalized and more than 1,000 died (26). The aim of the present work is to achieve an approximate estimation of the Covid-19 impact in our patients treated with bDMARDs for inflammatory rheumatic disease (IRD) and to compare it to a control group consisting of patients not treated with bDMARDs (i.e. IRD treated with cDMARDs and other musculo-skeletal conditions such as osteoarthritis, low back pain, tendinopathy etc.).

\section{Patients And Methods}

Design: Single-centre, observational cross-sectional case-control trial in 200 outpatients.

Patients: 100 consecutive patients, referred to the department of Rheumatology of the NFC hospital for an IRD, who have been treated with bDMARDs, were asked to complete a 15- item standardized questionnaire (the bDMARDs group). One hundred other consecutive patients who did not take bDMARDs 
completed the same questionnaire (the control group). Before being included in the study, patients were required to give their consent to the scientific and anonymous use of the data collected in the questionnaire. The survey was achieved in compliance with the reference methodology of the French Conseil National Informatique et Libertés Data Protection Council (CNIL MR-001). Patients were registered under a single number, in ascending order of inclusion (neither initials nor birth dates were registered). The following information was recorded: demographic data (gender, age, weight, height, body mass index), professional activity, family status, total number of children and number of children under 18, rheumatic disease diagnosis, current treatments for rheumatism, type of containment, close contact with Covid-19 patients, Covid-19 symptoms, Covid-19 test result and hospitalization for Covid-19.

Statistics: A descriptive analysis was performed on the collected data. Qualitative variables were described using frequencies and percentages. Quantitative variables were described using mean, standard deviation and the characteristics of their distribution (minimum, maximum and median). Between-group comparisons were achieved using a student $t$ test, chi-2 test or Fischer's exact test as appropriate. All statistical tests were carried out two-tailed at the $5 \%$ level of significance. The statistical analysis was performed using XLstats@ statistical and data analysis solution (Paris, France, 2020).

\section{Results}

bDMARD patients mostly suffered from rheumatoid arthritis (47\%) and ankylosing spondylitis (42\%). Ten suffered from psoriatic arthritis and only one from Horton disease. Five subjects with ankylosing spondylitis (AS) had also an inflammatory bowel disease. TNF a inhibitors were the most prescribed of the bDMARDs (57\%) (Table I) and the mean duration of the current biologic treatment was 38.6 months (range 1-180). Patients from the control group were suffering chiefly from osteoarthritis (45\%) and RA (21\%) (Table II).

The characteristics of both patient groups are summarized in table III. Patients treated with bDMARDs differed from those of the control group in age (10 years younger; $p<0.001)$ and the number of children under 18 ( 2 times less; $p=0.02$ ). As expected, they were also more likely to be retired ( $56 \%$ versus $31 \%$ ) and less likely to be on sick or incapacity leave (6\% versus $18 \%)$. However, those who were still working during the lockdown were more likely to have jobs requiring direct contact with the public or patients ( $13 \%$ versus $4 \%$ ). On the other hand, bDMARD patients were more likely to be working from home or working for only a short period of time ( $27 \%$ versus $9 \%$ ). Patients treated with bDMARDs have been less frequently in contact with Covid-19 patients, but the difference did not reach statistical significance $(p=0.16)$.

18 patients from the bDMARDs group stopped their biological treatment. Among them, only one stopped bDMARDs (Adalimumab) because of Covid-19 evidenced by PCR, 11 because of mild to moderate symptoms that suggested an infection and six asymptomatic subjects stopped treatment due to fear of contracting the disease. However, 12 patients, including the one Sars-CoV-2 +, resumed their treatment after a few weeks of interruption. There was no severe Covid-19 infection in the bDMARDs group. Among the three patients from the control group who had contracted Covid-19, a 72-year-old woman with 
osteoarthritis developed a very severe disease with ARDS, that required her to be admitted into the intensive care unit for mechanical ventilation. She recovered totally within two months.

\section{Discussion}

The first lesson we can learn from this study is that most patients treated with biologics continued treatment in accordance with the recommendations of the French Society of Rheumatology. Only $6 \%$ interrupted treatment for fear of the disease. The other patients who had to stop their biological treatment did so when they developed symptoms compatible with the Sars-Cov- 2 infection, and all of the patients resumed treatment after the symptoms had disappeared or once the PCR had been shown to be negative.

It is difficult to assert that patients with biologics are no more at risk of Covid-19 than control patients, since the number of infected subjects was very low in the two groups. However, our results suggest that taking a biologic is not a risk factor for contracting the disease. The only Covid-19 positive case was mild, unlike the control group where a patient, without significant risk factors except her age (72 years) developed a severe form requiring admission into the ICU.

However, it is possible that patients treated with biologics took more precaution during containment and that they were less in contact with sick subjects. Although they were more frequently in close contact with children under the age of 18 , they were on sick leave or working from home more often than the control subjects.

In conclusion, this case-control study, carried out in a region very strongly impacted by Covid-19, did not show an increase in the frequency or severity of the infection in subjects suffering from chronic inflammatory rheumatism treated with biotherapies.

Larger-scale studies, carried out outside a containment period, are necessary before affirming that biologics do not expose patients to an increased risk of disease and complications.

\section{Declarations}

\section{Contributions}

All authors contributed to data analysis, drafting or revising the article, gave final approval of the version to be published, and agree to be accountable for all aspects of the work.

\section{Ethics declarations}

\section{Conflict of interest}

The authors declare that they have no conflicts of interest.

\section{Ethical approval}


Due to the retrospective nature of the study, the Ethics Committee determined that only oral patient consent was required.

\section{Funding}

None

\section{Availability of data and materials}

All data generated or analysed during this study are available at the Unité de Recherche Clinique, Hôpital Nord Franche-Comté, Belfort, France.

\section{References}

1. Gorbalenya AE, Baker SC, Baric RS, de Groot RJ, Drosten C, Gulyaeva The species Severe acute respiratory syndrome-related coronavirus: classifying 2019-nCoV and naming it SARS-CoV-2. Nat Microbiol. 2020;5(4):536-544. doi: 10.1038/s41564-020-0695-z

2. Wu C, Chen X, Cai Y, Xia J, Zhou X, Xu S, et al. Risk Factors Associated With Acute Respiratory Distress Syndrome and Death in Patients With Coronavirus Disease 2019 Pneumonia in Wuhan, China. JAMA Intern Med. 2020 Mar 13. doi: 10.1001/jamainternmed.2020.0994

3. Bansal M. Cardiovascular disease and COVID-19. Diabetes Metab 2020;14(3):247-250. doi: 10.1016/j.dsx.2020.03.013.

4. Mao R, Qiu Y, He JS, Tan JY, Li XH, Liang J, et al. Manifestations and prognosis of gastrointestinal and liver involvement in patients with COVID-19: a systematic review and meta-analysis. Lancet Gastroenterol Hepatol. 2020. doi: 10.1016/S2468- 1253(20)30126-6

5. Parohan M, Yaghoubi S, Seraj A. Liver injury is associated with severe Coronavirus disease 2019 (COVID-19) infection: a systematic review and meta- analysis of retrospective studies. Hepatol Res. 2020. doi: 1111/hepr.13510

6. Wu Y, Xu X, Chen Z, Duan J, Hashimoto K, Yang L, et al. Nervous system involvement after infection with COVID-19 and other coronaviruses. Brain Behav Immun. 2020. pii: S0889-1591(20)30357-3. doi: 1016/j.bbi.2020.03.031.

7. Recalcati S. Cutaneous manifestations in COVID-19: a first perspective. J Eur Acad Dermatol 2020. doi: $10.1111 /$ jdv. 16387.

8. Joob B, Wiwanitkit Arthralgia as an initial presentation of COVID-19: observation. Rheumatol Int. 2020;40(5):823. doi: 10.1007/s00296-020-04561-0

9. Ferner RE, Aronson JK. Chloroquine and hydroxychloroquine in covid-19. 2020;369:m1432. doi: 10.1136/bmj.m1432. 
10. Touret F, de Lamballerie X. Of chloroquine and COVID-19. Antiviral Res. 2020 May;177:104762. doi: 1016/j.antiviral.2020.104762

11. Zhang W, Zhao Y, Zhang F, Wang Q, Li T, Liu Z, et al. The use of anti- inflammatory drugs in the treatment of people with severe coronavirus disease 2019 (COVID-19): The Perspectives of clinical immunologists from China. Clin Immunol. 2020; 214:108393. doi: 1016/j.clim.2020.108393.

12. Sarzi-Puttini P, Giorgi V, Sirotti S, Marotto D, Ardizzone S, Rizzardini G, et COVID-19, cytokines and immunosuppression: what can we learn from severe acute respiratory syndrome? Clin Exp Rheumatol. 2020;38(2):337-342

13. Tanaka T, Narazaki M, Kishimoto Immunotherapeutic implications of IL-6 blockade for cytokine storm. Immunotherapy. 2016;8(8):959-70. doi: 10.2217/imt- 2016-0020

14. Liu B, Li M, Zhou Z, Guan X, Xiang Can we use interleukin-6 (IL-6) blockade for coronavirus disease 2019 (COVID-19)-induced cytokine release syndrome (CRS)? J Autoimmun. 2020:102452. doi: 10.1016/j.jaut.2020.102452

15. Zhang C, Wu Z, Li JW, Zhao H, Wang GQ. The cytokine release syndrome (CRS) of severe COVID-19 and Interleukin-6 receptor (IL-6R) antagonist Tocilizumab may be the key to reduce the Int $\mathrm{J}$ Antimicrob Agents. 2020:105954. doi: 10.1016/j.ijantimicag.2020.105954

16. Xu X, Han M, Li T, Sun W, Wang D, Fu B, et al. Effective treatment of severe COVID-19 patients with Proc Natl Acad Sci U S A. 2020. pii: 202005615. doi: 10.1073/pnas.2005615117.

17. Luo P, Liu Y, Qiu L, Liu X, Liu D, Li J. Tocilizumab treatment in COVID-19: A single center experience. J Med Virol. 2020 doi: 10.1002/jmv.25801.

18. Ferro F, Elefante E, Baldini C, Bartoloni E, Puxeddu I, Talarico R, et al.COVID-19: the new challenge for rheumatologists. Clin Exp Rheumatol. 2020; 38(2):175-180

19. González-Gay MA, Mayo J, Castañeda S, Cifrián JM, Hernández-Rodríguez J. Tocilizumab: From the Rheumatology Practice to the Fight Against COVID-19, a virus infection with multiple faces. Expert Opin Biol 2020. doi: 10.1080/14712598.2020.1770222

20. Klopfenstein T, Zayet S, Lohse A, Balblanc JC, Badie J, Royer PY et Tocilizumab therapy reduced intensive care unit admissions and/or mortality in COVID-19 patients. Med Mal Infect. 2020:S0399077X(20)30129-3. doi: 10.1016/j.medmal.2020.05.00

21. Lohse A, Klopfenstein T, Balblanc JC, Royer PY, Bossert M, Gendrin V, et Predictive factors of mortality in patients treated with tocilizumab for acute respiratory distress syndrome related to coronavirus disease 2019 (COVID-19).Microbes Infect. 2020:S1286-4579(20)30123-4. doi:10.1016/j.micinf.2020.06.005.

22. Conrozier T, Lohse A, Balblanc JC, Dussert P, Royer PY, Bossert M, et Biomarker variation in patients successfully treated with tocilizumab for severe coronavirus disease 2019 (COVID-19): results of a multidisciplinary collaboration. Clin Exp Rheumatol. 2020 Jun 23. 
23. Ramiro S, Sepriano A, Chatzidionysiou K, Nam JL, Smolen JS, van der Heijde D et al. Safety of synthetic and biological DMARDs: a systematic literature review informing the 2016 update of the EULAR recommendations for management of rheumatoid arthritis. Ann Rheum Dis. 2017;76(6):11011136. doi: 10.1136/annrheumdis-2016-210708.

24. Figuero-Pérez L, Olivares-Hernández A, Escala-Cornejo RA, Terán-Brage E, López-Gutiérrez Á, CruzHernández JJ. Anakinra as a potential alternative in the treatment of severe acute respiratory infection associated with SARS-CoV-2 refractory to tocilizumab Reumatol Clin. 2020:S1699258X(20)30142-X. doi: 10.1016/j.reuma.2020.06.003

25. Pop R, Quenardelle V, Hasiu A, Mihoc D, Sellal F, Dugay MH, et al. Impact of the Covid-19 outbreak on acute stroke pathways - Insights from the Alsace region in France. Eur J Neurol. 2020. doi: 1111/ene.14316

26. https://www.fr/info-coronavirus/carte-et-donnees

\section{Tables}

Table I: List of the Biological Disease Modifying Anti-Rheumatic Drugs (bDMARDs group)

\begin{tabular}{rr} 
bDMARDS Number o \\
ABATACEPT & 4 \\
\hline ADALIMUMAB & 19 \\
\hline BARICITINIB & 7 \\
\hline CERTOLIZUMAB & 1 \\
\hline ETANERCEPT & 15 \\
\hline GOLIMUMAB & 13 \\
\hline INFLIXIMAB & 9 \\
\hline IXEKIZUMAB & 1 \\
\hline RITUXIMAB & 4 \\
\hline SARILUMAB & 1 \\
\hline SECUKINUMAB & 7 \\
\hline TOCILIZUMAB & 11 \\
\hline TOFACITINIB & 4 \\
\hline USTEKINUMAB & 4
\end{tabular}

Table II: Rheumatic diseases in the control group 


\begin{tabular}{|c|c|}
\hline Rheumatic diseases & Number of subjects \\
\hline Osteoarthritis & 45 \\
\hline Rheumatoid arthritis & 21 \\
\hline Polymyalgia rheumatic/ Horton disease & 7 \\
\hline Ankylosing spondylitis & 6 \\
\hline Tendinopathy & 6 \\
\hline Fibromyalgia & 3 \\
\hline Chondrocalcinosis & 3 \\
\hline Sciatica & 3 \\
\hline Systemic lupus erythematosus & 2 \\
\hline Others (meniscopathy, villonodular synovitis, SAPHO syndrome, Infectious spondylodiscitis) & 4 \\
\hline
\end{tabular}

Table III: Characteristics of patients treated with Biological Disease Modifying Anti- Rheumatic Drugs (bDMARDs) or not (Controls) 


\begin{tabular}{|c|c|c|c|c|}
\hline Age (years) Mean (range) & $59(23-89)$ & $54(25-81)$ & $64(23-89)$ & $<0.001$ \\
\hline Weight (kg) Mean (range) & $75.3(41-145)$ & $75.7(45-121)$ & $74.5(41-145)$ & 0.64 \\
\hline Height (cm) Mean (range) & $166.4(140-195)$ & $166.4(148-187)$ & $165.8(140-195)$ & 0.62 \\
\hline Body Mass Index Mean (range) & $27.2(16.8-48.1)$ & $27.3(17.9-48.1)$ & $27.0(16.8-44.9)$ & 0.74 \\
\hline Sex ratio $(F / M)$ & $127 / 93$ & $62 / 48$ & $65 / 45$ & 0.66 \\
\hline Nb children Mean (range) & $1.71(0-5)$ & $1.7(0-5)$ & $1.78(0-4)$ & 0.87 \\
\hline $\begin{array}{l}\mathrm{Nb} \text { of children }<18 \\
\text { Mean (range) }\end{array}$ & $0.54(0-5)$ & $0.7(0-5)$ & $0.36(0-3)$ & 0.02 \\
\hline Life in couple/alone $(\mathrm{N})$ & $156 / 44$ & $80 / 20$ & $76 / 24$ & 0.69 \\
\hline Retired (\%) & 87 & 31 & 56 & 0.001 \\
\hline Sick or incapacity leave (\%) & 48 & 31 & 17 & 0.02 \\
\hline Working from home/short-term working (\%) & 36 & 27 & 9 & $<0.0001$ \\
\hline Work with public or patients (\%) & 17 & 4 & 13 & 0.01 \\
\hline Methotrexate or leflunomide (\%) & 47 & 29 & 18 & 0.04 \\
\hline Corticosteroid (\%) & 13 & 7 & 6 & 0.90 \\
\hline Covid-19 symptoms (yes/no) & $27 / 173$ & $12 / 88$ & $15 / 85$ & 0.45 \\
\hline PCR assessment (\%) & 11 & 4 & 7 & 0.55 \\
\hline $\mathrm{PCR}+(\%)$ & 4 & 1 & 3 & 0.84 \\
\hline Contact with Covid-19 subject (yes/no/uncertain) & $27 / 156 / 18$ & $10 / 84 / 6$ & $17 / 72 / 11$ & 0.16 \\
\hline Stop bioM (yes/no) & $18 / 182$ & $18 / 82$ & NA & NA \\
\hline
\end{tabular}

